\title{
Energy transfer between terbium and europium ions in barium orthosilicate phosphors obtained from sol-gel route
}

\author{
Airton G. Bispo-Jr ${ }^{\mathrm{a}, \mathrm{b}}$, Sergio A.M. Lima ${ }^{\mathrm{a}, \mathrm{b}}$, Ana. M. Pires ${ }^{\mathrm{a}, \mathrm{b}, *}$ \\ a São Paulo State University (Unesp), School of Technology and Sciences, Presidente Prudente, SP 19060-900, Brazil

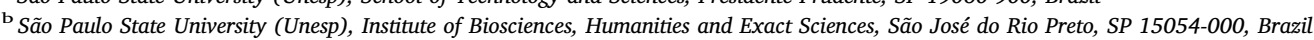

\section{A R T I C L E I N F O}

\section{Keywords:}

Silicate

Europium

Terbium

Energy transfer

Van Uitert theory

Spectroscopic probe

\begin{abstract}
A B S T R A C T
The present paper reports on the energy transfer mechanism between $\mathrm{Eu}^{3+}$ and $\mathrm{Tb}^{3+}$ in barium orthosilicate obtained from the sol-gel route, when both activators concentration is varied. The synthetic methodology was adjusted to provide high crystalline and monophasic $\mathrm{Ba}_{2} \mathrm{SiO}_{4}$. In the emission spectra under $250 \mathrm{~nm}$ excitation, both $\mathrm{Eu}^{3+}\left({ }^{5} \mathrm{D}_{0} \rightarrow{ }^{7} \mathrm{~F}_{\mathrm{J}}\right)$ and $\mathrm{Tb}^{3+}\left({ }^{5} \mathrm{D}_{3} \rightarrow{ }^{7} \mathrm{~F}_{\mathrm{J}}\right.$ and $\left.{ }^{5} \mathrm{D}_{4} \rightarrow{ }^{7} \mathrm{~F}_{\mathrm{J}}\right)$ transitions can be observed at low Eu ${ }^{3+}$ doping concentrations with an unexpected and intense blue emission from $\mathrm{Tb}^{3+}$. However, when the $\mathrm{Eu}^{3+}$ content is higher than that of the $\mathrm{Tb}^{3+}$, just the $\mathrm{Eu}^{3+}$ emission is noticed. Also, it is possible to tune the phosphor emission from red to pink by varying the $\mathrm{Eu}^{3+}$ and $\mathrm{Tb}^{3+}$ content. From the excitation spectra, we inferred that energy transfer (ET) from $\mathrm{Tb}^{3+}$ to $\mathrm{Eu}^{3+}$ occurs at any doping situation, nonetheless, the opposite process happens just when both activators amount is similar. An approach using the $\mathrm{Tb}^{3+}$ and $\mathrm{Eu}^{3+}$ lifetimes and the $\mathrm{Eu}^{3+}$ quantum efficiency confirms this observation, indicating that not only the matrix act as sensitizer to the $\mathrm{Eu}^{3+}$ ions, but also $\mathrm{Tb}^{3+}$ ions contribute by increasing the $\mathrm{Eu}^{3+}$ quantum efficiency in up to $20 \%$. Finally, by using the Van Uitert theory, it was found for this system that the ET between the two rare-earth ions is dominated by the dipole-dipole mechanism.
\end{abstract}

\section{Introduction}

Rare earth (RE)-doped nanophosphors display unique optical properties that combined with good thermal and chemical stability, make these systems suitable for luminescence and photonic applications [1]. In special, RE-doped barium orthosilicate have been used in solid state lighting devices as white light emitting diode (w-LEDs) [2,3] which are replacing fluorescent and incandescent light sources due to their high energy conversion efficiency resulting in an energy saving, compactness, and long duration time $[4,5] . \mathrm{Eu}^{3+}$ ion, for instance, is an efficient red emitting activator due to its emission lines that arise from the ${ }^{5} \mathrm{D}_{0}$ excited level to the ${ }^{7} \mathrm{~F}_{\mathrm{J}}(\mathrm{J}=0,1,2,3,4,5,6)$ ground levels $[6,7]$. Also, the relative intensity, position and degenerescence of $\mathrm{Eu}^{3+}$ transitions are dependent on the host lattice nature, chemical composition and crystalline structure, allowing its use as structural probes [8]. $\mathrm{Tb}^{3+}$, in turn, has two main emission levels ${ }^{5} \mathrm{D}_{4}$, and ${ }^{5} \mathrm{D}_{3}$ [9]. The transitions from the first one to the ground ${ }^{7} \mathrm{~F}_{\mathrm{J}}$ levels result in green emission, while the transitions from the second one is less common, resulting in blue emission, and depend on the $\mathrm{Tb}^{3+}$ concentration, and on the crystal structure and phonon frequency of the matrix [10]. $\mathrm{Ba}_{2} \mathrm{SiO}_{4}$ is an inorganic insulator matrix widely used to host $\mathrm{RE}$ activators due its relative low phonon frequency $\left(\sim 900 \mathrm{~cm}^{-1}\right)$ and high structural, thermal and electrical stability $[11,12]$. For the best of your knowledge, no study has been reported about the synthesis of barium orthosilicate simultaneously doped with $\mathrm{Eu}^{3+}$ and $\mathrm{Tb}^{3+}$, while recently, we reported the synthesis of the $\mathrm{Eu}^{3+}$-doped $\mathrm{Ba}_{2} \mathrm{SiO}_{4}$ from the sol gel-route [13]. On the other side, many reports on the synthesis of $\mathrm{Eu}^{3+}$ and $\mathrm{Tb}^{3+}$-codoped phosphors based on host lattices distinct from $\mathrm{Ba}_{2} \mathrm{SiO}_{4}$ can be found in the literature, aiming application in white LEDs devices [14-18]. As example, M. A. Tshabalala et al. [19] described the solid state synthesis of $\mathrm{Eu}^{3+}$ and $\mathrm{Tb}^{3+}$-doped strontium orthosilicate and its white emission under UV excitation. However, one of the challenges concerning these codoped phosphors is to understand the energy transfer (ET) mechanism between $\mathrm{Eu}^{3+}$ and $\mathrm{Tb}^{3+}$ ions in order to modulate the phosphor white emission. Indeed, there is a lack in the literature about this kind of approach dealing with ET between these ions specifically in barium orthosilicate matrix. In this paper, we report the synthesis of $\mathrm{Eu}^{3+}$ and $\mathrm{Tb}^{3+}$-codoped barium orthosilicate phosphor from the sol-gel route, and we propound a detailed interpretation of the ET process by varying the concentration of the two activator ions in order to use $\mathrm{Tb}^{3+}$, along with the matrix, as sensitizer for the $\mathrm{Eu}^{3+}$ emission.

\footnotetext{
* Corresponding author at: São Paulo State University (Unesp), School of Technology and Sciences, R. Roberto Simonsen, 305, 19060-900 Presidente Prudente, SP, Brazil.

E-mail address: ana.maria@unesp.br (A.M. Pires).
} 


\section{Experimental}

The $\mathrm{Tb}^{3+}$ and $\mathrm{Eu}^{3+}$-codoped $\mathrm{Ba}_{2} \mathrm{SiO}_{4}$ powder samples were synthesized by applying an adapted sol-gel route developed in our research group $[13,20]$. Tetraethylorthosilicate (TEOS, $\mathrm{C}_{8} \mathrm{H}_{20} \mathrm{O}_{4} \mathrm{Si}, 99.9 \%$, Fluka), hydrogen peroxide $\left(\mathrm{H}_{2} \mathrm{O}_{2}, 36 \%\right.$, Synth), acetic acid $\left(\mathrm{CH}_{3} \mathrm{COOH}\right.$, $97 \%$, VETEC), barium acetate $\left(\mathrm{Ba}\left(\mathrm{CH}_{3} \mathrm{COO}\right)_{2}, 99.9 \%\right.$, VETEC), europium oxide $\left(\mathrm{Eu}_{2} \mathrm{O}_{3}, 99.99 \%\right.$, Aldrich), hydrochloric acid ( $\mathrm{HCl}, 37 \%$, Sigma), and terbium oxide $\left(\mathrm{Tb}_{4} \mathrm{O}_{7}, 99.99 \%\right.$, Aldrich) were used as reactants. Europium acetate $\left(\mathrm{Eu}\left(\mathrm{CH}_{3} \mathrm{COO}\right)_{3}\right)$ and terbium chloride $\left(\mathrm{TbCl}_{3}\right)$ solutions were prepared by dissolving the RE oxide in hot acetic acid or hydrochloric acid, respectively. For the complete dissolution of the $\mathrm{Tb}_{4} \mathrm{O}_{7}$, it was necessary the addition of some drops of $\mathrm{H}_{2} \mathrm{O}_{2}$. The xerogel precursors for the $\mathrm{Ba}_{2} \mathrm{SiO}_{4}$ powders were synthesized by dissolving stoichiometric amount of $\mathrm{Ba}\left(\mathrm{CH}_{3} \mathrm{COO}\right)_{2}, \mathrm{Eu}\left(\mathrm{CH}_{3} \mathrm{COO}\right)_{3}$ and $\mathrm{TbCl}_{3}$ in acetic acid $(10 \mathrm{~mL})$, aiming to obtain $1.0000 \mathrm{~g}$ of $\mathrm{Ba}_{\mathrm{x}} \mathrm{Eu}_{\mathrm{y}} \mathrm{Tb}_{\mathrm{z}} \mathrm{SiO}_{4}$ powder. Following, TEOS $(0.55 \mathrm{M}$, in isopropyl alcohol) was stoichiometrically added in the solution containing the metal precursors. The solution was kept under magnetic stirring for $4 \mathrm{~h}$ ( $35^{\circ} \mathrm{C}$ ) until the gel precursor formation. The gel was dried at $120^{\circ} \mathrm{C}$ for $2 \mathrm{~h}$, resulting in the xerogel phase. Finally, the xerogel precursor was calcinated at $1100{ }^{\circ} \mathrm{C}$ for $2 \mathrm{~h}$ with a heating ramp of $10^{\circ} \mathrm{C} / \mathrm{min}$ in an EDG muffle furnace type, under a circulating air atmosphere, obtaining the phosphor particles. The $\mathrm{Eu}^{3+}$ and $\mathrm{Tb}^{3+}$ amounts were isoelectronically varied in order to keep the same overall charge in the system, according to the $\mathrm{Ba}^{2+}, \mathrm{Eu}^{3+}, \mathrm{Tb}^{3+}$ and $\mathrm{SiO}_{4}^{4-}$ charges $\left(3 n_{E u^{3+}}+3 n_{T b^{3+}}+2 n_{B a^{2+}}=+4\right.$, where $n_{B a^{2+}}, n_{T b^{3+}}$ and $n_{E u^{3+}}$ are the mol number of $\mathrm{Ba}^{2+}, \mathrm{Tb}^{3+}$ and $\mathrm{Eu}^{3+}$, respectively). The stoichiometric amounts of $\mathrm{Eu}^{3+}, \mathrm{Tb}^{3+}$ and $\mathrm{Ba}^{2+}$ ions in each phosphor are shown in the Supplementary material, Table ES1, and the samples synthesized are listed in Table 1.

Powder crystalline structure was checked by using a SIEMENS diffractometer model D5000, $\mathrm{Cu} \mathrm{K \alpha}$ radiation $(\lambda=1,5405 \AA)$, a $2 \theta$ range of $20-45^{\circ}$, an increment of $0.02^{\circ}$ and integration time of $1 \mathrm{~s}$. The samples were also characterized by scanning electron microscopy (SEM) using a Carls Zeiss model EVO LS15 microscope with a detector of secondary electrons (SE) in high vacuum and constant temperature. Finally, photoluminescence measurements at room temperature were carried out in a Horiba JobinYvon spectrometer Fluorolog-3 with a Xe lamp ( $450 \mathrm{~W}$ ) source with double excitation monochromator. Emission lifetime was evaluated using a phosphorimeter equipped with $\mathrm{Xe}(5 \mathrm{~J} /$ pulse) lamp.

Table 1

$\mathrm{Tb} / \mathrm{Eu}$ emission rate, and critical distance $\left(\mathrm{R}_{\mathrm{c}}\right)$ between $\mathrm{Eu}^{3+}$ and $\mathrm{Tb}^{3+}$ ions.

\begin{tabular}{lllll}
\hline Tb/ Eu (\%) & $\begin{array}{l}\text { Tb/Eu emission } \\
\text { rate }^{\mathrm{a}}\end{array}$ & $\begin{array}{l}\mathbf{R}_{\mathbf{c}} \text { Eu-Eu/ } \\
\AA^{\mathrm{b}}\end{array}$ & $\begin{array}{l}\mathbf{R}_{\mathbf{c}} \mathbf{T b}-\mathbf{T b} / \\
\AA^{\mathrm{b}}\end{array}$ & $\begin{array}{l}\mathbf{R}_{\mathbf{c}} \text { Eu-Tb } \\
\AA^{\mathrm{b}}\end{array}$ \\
\hline $2 / 2$ & 1.19 & 8.54 & 8.54 & 6.78 \\
$2 / 0.1$ & 0.09 & 23.5 & 8.62 & 8.49 \\
$1 / 3$ & - & 7.46 & 10.8 & 6.78 \\
$1 / 2$ & 0.58 & 8.58 & 10.8 & 7.50 \\
$1 / 1$ & 0.92 & 8.67 & 10.9 & 8.63 \\
$1 / 0.1$ & 0.48 & 23.5 & 10.9 & 10.6 \\
$1 / 0.05$ & 0.59 & 29.7 & 10.9 & 10.7 \\
$1 / 0.01$ & 0.34 & 50.7 & 10.9 & 10.9 \\
$0.5 / 4$ & - & 6.76 & 13.5 & 6.50 \\
$0.5 / 1$ & 1.13 & 10.90 & 13.7 & 9.52 \\
$0.5 / 0.5$ & 0.96 & 13.7 & 13.7 & 10.9 \\
$0.1 / 4$ & - & 6.77 & 23.2 & 10.4 \\
\end{tabular}

a The $\mathrm{Tb} / \mathrm{Eu}$ emission rate parameter was determined by the rate between the sum of the integrated area below the Terbium and Europium transitions in the emission spectra under excitation at $250 \mathrm{~nm}$.

b The Ln-Ln distance was calculated considering the $\mathrm{Ln}^{3+}$ concentration in Eq. (2).

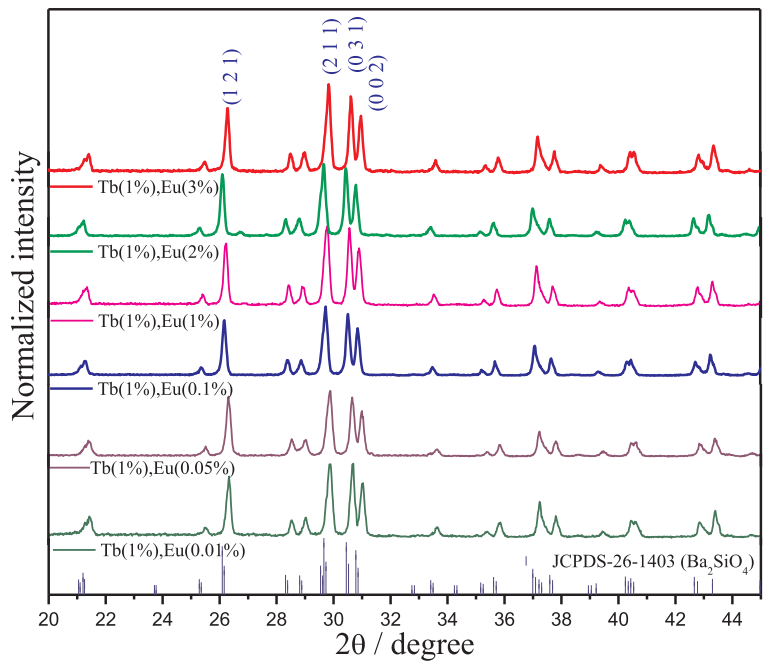

Fig. 1. Powder X-ray diffractograms of the phosphors doped with $1 \%$ of $\mathrm{Tb}^{3+}$ and varying the $\mathrm{Eu}^{3+}$ content.

\section{Results}

X-ray diffraction (XRD) patterns of representative samples are shown in Fig. 1 and for all other samples, the results are shown in Fig. S1, Supplementary material. XRD data confirm that the phosphors obtained by the sol-gel route at $1100{ }^{\circ} \mathrm{C}$ are crystalline, with orthorhombic crystal system (JCPDS 26-1403 card), and $P_{\text {man }}$ space group. Regarding the limit of detection of this technique, there is no evidence of $\mathrm{Eu}_{2} \mathrm{O}_{3}$ and $\mathrm{Tb}_{4} \mathrm{O}_{7}$ formation, which corroborate for the fact that both activator ions are inserted into the $\mathrm{Ba}_{2} \mathrm{SiO}_{4}$ lattice and can occupy two different sites, one with coordination number (CN) 9 and another with CN 10 [21]. In addition, the mean crystallite size calculated via Scherrer's method [22], varied from 49 to $76 \mathrm{~nm}$ for all produced samples. The full data are included in the Supplementary material, Table ES2. Moreover, it is clear that the increase of the $\mathrm{Eu}^{3+}$ concentration in relation to the $\mathrm{Tb}^{3+}$ leads to an increase in the mean diameter of the crystallites.

SEM images of some representative phosphors are shown in Fig. S2, in the Supplementary material. The observed particles are irregular in shape and size, yet the mean size was estimated at about $330 \mathrm{~nm}$, and some particles are spherical while others are ellipsoidal shaped.

Fig. 2 exhibits the photoluminescence excitation spectra of the codoped phosphors monitoring the ${ }^{5} \mathrm{D}_{0} \rightarrow{ }^{7} \mathrm{~F}_{2}$ transition of $\mathrm{Eu}^{3+}$ at $612 \mathrm{~nm}$. The most intense band observed in the excitation spectra at high energies is assigned to both $\mathrm{Tb}^{3+}{ }^{7} \mathrm{~F}_{6} \rightarrow 4 \mathrm{f}^{7} 5 \mathrm{~d}$ transition and $\mathrm{O}^{2-} \rightarrow$ $\mathrm{Eu}^{3+}$ charge transfer. The magnification of the range within $325-500 \mathrm{~nm}$ shows the $\mathrm{Eu}^{3+}$ and the $\mathrm{Tb}^{3+} f-f$ transitions in all spectra, indicating that the $\mathrm{Eu}^{3+}$ emission arises from both $\mathrm{RE}^{3+}$ excitation. This observation lead us to conclude that the ET from $\mathrm{Tb}^{3+}$ to $\mathrm{Eu}^{3+}$ ions $\left(\mathrm{Tb}^{3+} \rightarrow \mathrm{Eu}^{3+}\right)$ is taking place in all phosphors. The ET between the two ions is favored because the energies of the ${ }^{5} \mathrm{D}_{3}\left(26,402 \mathrm{~cm}^{-1}\right)$ and ${ }^{5} \mathrm{D}_{4} \quad\left(20,640 \mathrm{~cm}^{-1}\right) \quad$ [23] levels of $\mathrm{Tb}^{3+}$ ions, and the ${ }^{5} \mathrm{D}_{0}$ $\left(17,280 \mathrm{~cm}^{-1}\right), \quad{ }^{5} \mathrm{D}_{1} \quad\left(18,973 \mathrm{~cm}^{-1}\right),{ }^{5} \mathrm{D}_{2} \quad\left(21,445 \mathrm{~cm}^{-1}\right)$, and ${ }^{5} \mathrm{D}_{3}$ $(24,335)[6]$ levels of $\mathrm{Eu}^{3+}$ ions are close enough to allow the resonance between them.

In the emission spectra recorded with excitation wavelength fixed at $250 \mathrm{~nm}$, Fig. 3, both ions are excited via $\mathrm{Tb}^{3+}{ }^{7} \mathrm{~F}_{6} \rightarrow 4 \mathrm{f}^{7} 5 \mathrm{~d}$ and $\mathrm{O}^{2-} \rightarrow$ $\mathrm{Eu}^{3+}$ transitions, resulting in green and blue emission from $\mathrm{Tb}^{3+}$, and red emission from $\mathrm{Eu}^{3+}$. When the $\mathrm{Eu}^{3+}$ content is much higher than that of $\mathrm{Tb}^{3+}$, the $\mathrm{Tb}^{3+}$ emission is neglected, just the matrix intrinsic emission is observed in the blue range (see the matrix intrinsic luminescent profile in Fig. S4).

The $\mathrm{Eu}^{3+}$ red emission comes from the ${ }^{5} \mathrm{D}_{0} \rightarrow{ }^{7} \mathrm{~F}_{0,1,2,3,4}$ transitions, attributed to $\mathrm{Eu}^{3+}$ ions occupying low-symmetry sites [24]. The $\mathrm{Tb}^{3+}$ 

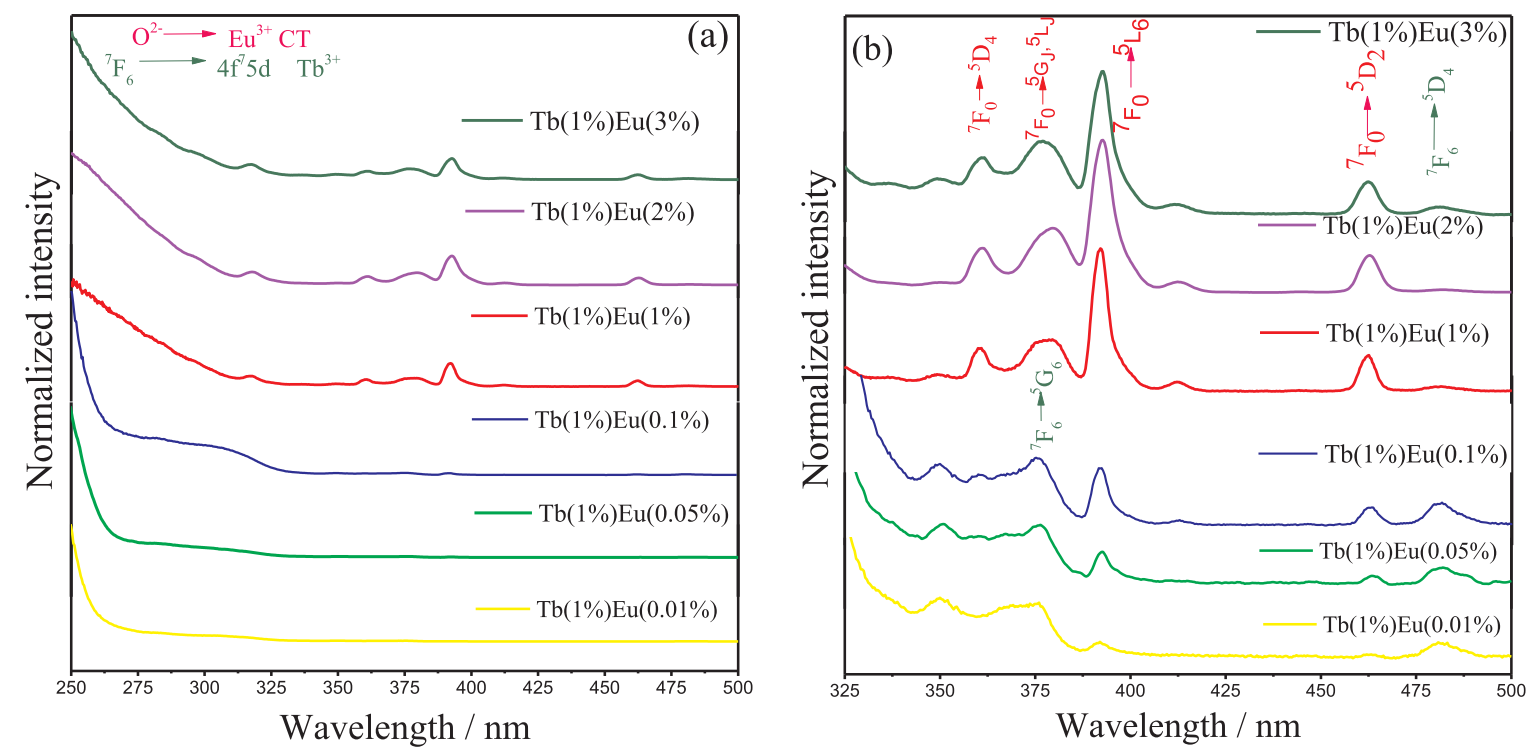

Fig. 2. Excitation spectra of $\mathrm{Ba}_{2} \mathrm{SiO}_{4}: \mathrm{Tb}^{3+}, \mathrm{Eu}^{3+}$ samples measured at room temperature. The emission wavelength was fixed in the Eu ${ }^{3+}$ emission at $612 \mathrm{~nm}$ (a). Magnification of the range between 325 and $500 \mathrm{~nm}$, where $\mathrm{Tb}^{3+}$ transitions assignments are shown in green and the Eu ${ }^{3+}$ ones in red (b). The excitation spectra of the other phosphors are shown in Fig. ES3.

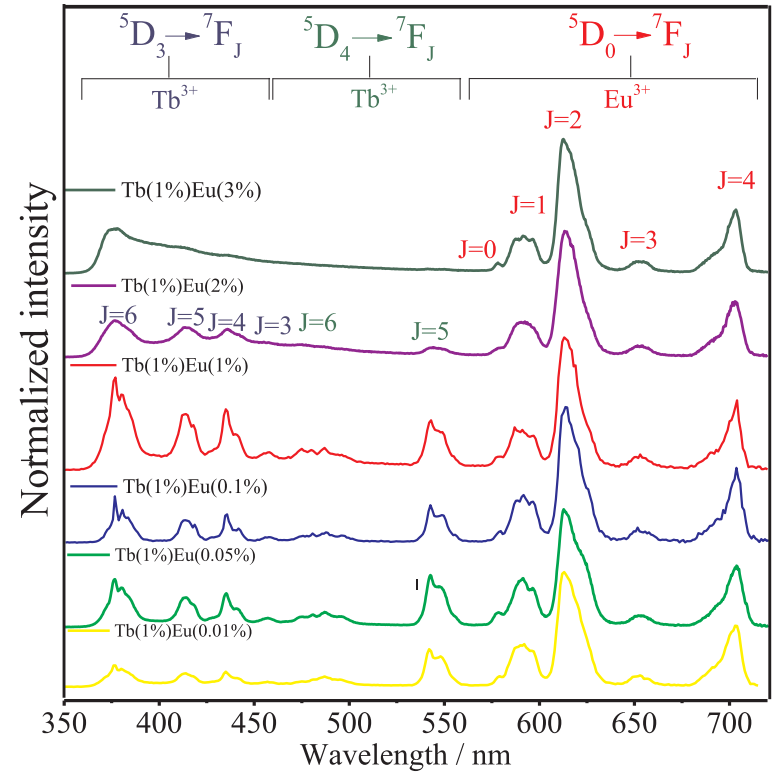

Fig. 3. Emission spectra of $\mathrm{Ba}_{2} \mathrm{SiO}_{4}: \mathrm{Tb}^{3+}, \mathrm{Eu}^{3+}$ samples measured at room temperature. The emission spectra of the other phosphors are shown in Fig. S5. The excitation wavelength was fixed in $250 \mathrm{~nm}$. $\mathrm{Tb}^{3+}$ transitions assignments are shown in green and blue and $\mathrm{Eu}^{3+}$ in red.

blue emission, in turn, is assigned to transitions from the ${ }^{5} \mathrm{D}_{3}$ excited level while the green emission comes from the ${ }^{5} \mathrm{D}_{4}$ level to the ${ }^{7} \mathrm{~F}_{J}$ ground level. Usually, the $\mathrm{Tb}^{3+}$ blue emission is very weak due to the cross relaxation mechanism involving the ${ }^{5} \mathrm{D}_{3}$ and ${ }^{5} \mathrm{D}_{4}$ levels which quenches the ${ }^{5} \mathrm{D}_{3}$ emission (see Eq. (1)) [25]. However, when the $\mathrm{Tb}^{3+}$ concentration is low, the Tb-Tb distance is long enough to inhibit the cross relaxation, favoring the blue emission from the ${ }^{5} \mathrm{D}_{3}$ level. In literature, the $\mathrm{Tb}^{3+}$ blue emission is reported for concentration less than 0.01 at $\%[10,25]$, but in the present case, the intense blue emission begins to take place at $\mathrm{Tb}^{3+}$ concentrations relatively high $(\sim 1 \%)$. Also, host matrix with phonon energy lower than $1000 \mathrm{~cm}^{-1}$ favors the ${ }^{5} \mathrm{D}_{3}$ blue emission due to the absence of multi phonon relaxation [26]. The phonon energy in the barium orthosilicate is $900 \mathrm{~cm}^{-1}$ [26], then the multiphonon relaxation process that can compete with the ${ }^{5} \mathrm{D}_{3}$ radiative emission is unlikely to take place, since the multiphonon mechanism is limited by the coupling of a maximum of 4 or 5 phonons [26].

$\mathrm{Tb}^{3+}\left({ }^{5} \mathrm{D}_{3}\right)+\mathrm{Tb}^{3+}\left({ }^{7} \mathrm{~F}_{6}\right) \rightarrow \mathrm{Tb}^{3+}\left({ }^{5} \mathrm{D}_{4}\right)+\mathrm{Tb}^{3+}\left({ }^{7} \mathrm{~F}_{0}\right)$

The rate between terbium and europium emission integrated areas for all phosphors is listed in Table 1 . For the samples doped with $1 \%$ of $\mathrm{Tb}^{3+}$, the increase of $\mathrm{Eu}^{3+}$ concentration leads to an increment in the $\mathrm{Tb}^{3+}$ emission up to $1 \%$ of $\mathrm{Eu}^{3+}$. Then, the $\mathrm{Eu}^{3+}$ emission overcomes the $\mathrm{Tb}^{3+}$ one. This behavior leads us to conclude that $\mathrm{ET}$ from $\mathrm{Eu}^{3+}$ to $\mathrm{Tb}^{3+}\left(\mathrm{Eu}^{3+} \rightarrow \mathrm{Tb}^{3+}\right)$ dominates the ET up to $1 \%$ of $\mathrm{Eu}^{3+}$, and at higher $\mathrm{Eu}^{3+}$ concentrations, on the other side, the $\mathrm{Tb}^{3+} \rightarrow \mathrm{Eu}^{3+} \mathrm{ET}$ is the main process. The same profile is observed for samples doped with $0.5 \%$ of $\mathrm{Tb}^{3+}$.

The $\mathrm{Eu}^{3+} \rightarrow \mathrm{Tb}^{3+}$ ET mechanism proposition is indorsed by analyzing the excitation spectra monitoring the $\mathrm{Tb}^{3+}{ }^{5} \mathrm{D}_{4} \rightarrow{ }^{7} \mathrm{~F}_{5}$ emission (Fig. S6), where the $\mathrm{Eu}^{3+}{ }^{7} \mathrm{~F}_{0} \rightarrow{ }^{5} \mathrm{~L}_{6}$ transition is observed for the sample doped with $1 \%$ of $\mathrm{Eu}^{3+}$ and $\mathrm{Tb}^{3+}$, indicating that $\mathrm{Tb}^{3+}$ emission can be achieved via $\mathrm{Eu}^{3+}$ excitation. For the samples with low $\mathrm{Eu}^{3+}$ concentrations, the $\mathrm{Eu}^{3+}$ excitation cannot be observed because the $\mathrm{Ba}_{2} \mathrm{SiO}_{4}$ intrinsic excitation overcomes the $\mathrm{Tb}^{3+}$ lines.

An extrapolation of $\mathrm{Eu}^{3+}$-doping in relation to the $\mathrm{Tb}^{3+}$ concentration (sample doped with $0.1 \%$ of $\mathrm{Tb}^{3+}$ and $4 \%$ of $\mathrm{Eu}^{3+}$ ) shows that the $\mathrm{Tb}^{3+}$ emission is quenched when the $\mathrm{Eu}^{3+}$ content is too high. In addition, when both $\mathrm{Eu}^{3+}$ and $\mathrm{Tb}^{3+}$ doping are the same, the $\mathrm{Tb}^{3+}$ and $\mathrm{Eu}^{3+}$ emission intensity are similar, probably because the $\mathrm{Eu}^{3+} \rightarrow \mathrm{Tb}^{3+}$ and $\mathrm{Tb}^{3+} \rightarrow \mathrm{Eu}^{3+}$ ET rates are too close in these cases. Therefore, the $\mathrm{Eu} \rightarrow \mathrm{Tb}$ ET occurs just when both the $\mathrm{Eu}^{3+}$ and $\mathrm{Tb}^{3+}$ content are close.

Fig. 4 shows some propositions of ET mechanisms between $\mathrm{Tb}^{3+}$ and $\mathrm{Eu}^{3+}$ in $\mathrm{Ba}_{2} \mathrm{SiO}_{4}$ host. In the mechanism I, both $\mathrm{Eu}^{3+}$ and $\mathrm{Tb}^{3+}$ emit under $250 \mathrm{~nm}$ excitation. In the mechanism II, the ET from $\mathrm{Tb}^{3+}$ to $\mathrm{Eu}^{3+}$ is shown and occurs for all samples, dominating the ET profile at high $\mathrm{Eu}^{3+}$ concentrations. In the case of mechanism III, the ET from $\mathrm{Eu}^{3+}$ to $\mathrm{Tb}^{3+}$ is represented and dominate the ET between the RE ions just for samples with low $\mathrm{Eu}^{3+}$ doping concentrations.

Usually, the energy transfer among RE ions involves radiation reabsorption, exchange or multipole-multipole interactions [27]. However, in the present system, the radiation reabsorption mechanism is unlikely to take place because it requires a wide overlap between the donor emission and acceptor excitation spectra, which is not observed 


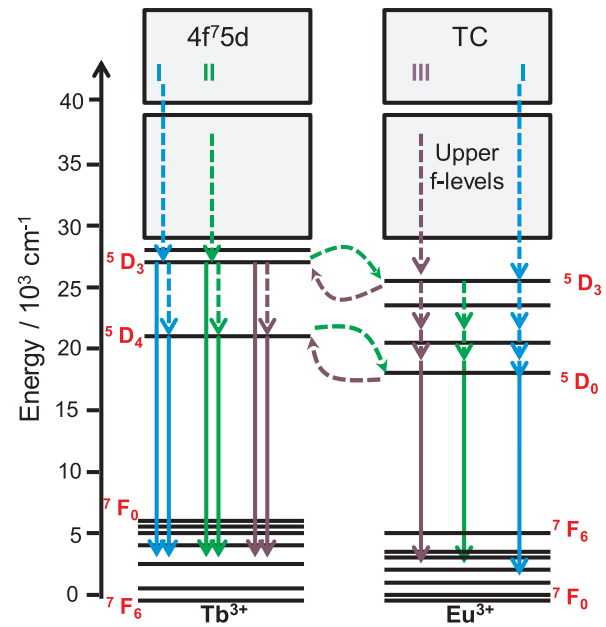

Fig. 4. Energy transfer mechanisms between $\mathrm{Tb}^{3+}$ and $\mathrm{Eu}^{3+}$ ions (dashed arrows: non-radiative transitions; solid line arrows: radiative transitions, curved lines: energy transfer). The mechanism I (blue lines) represent the emission from both RE ions under excitation at $250 \mathrm{~nm}$ without energy transfer. The mechanism II (green lines) represent the $\mathrm{Tb}^{3+} \rightarrow \mathrm{Eu}^{3+}$ ET and the emission from both RE ions. The mechanism III (purple lines) represent the $\mathrm{Eu}^{3+} \rightarrow \mathrm{Tb}^{3+}$ ET and both RE emissions. (For interpretation of the references to color in this figure legend, the reader is referred to the web version of this article.)

in this system. Considering the exchange coupling possibility, it is necessary to evaluate the critical distance $\left(R_{c}\right)$ between the donor and acceptor because this mechanism is limited by $4 \AA$ to allow an orbital overlap [28]. In this context, the critical distance was determinate by using Eq. (2) [29], where $n_{\mathrm{A}}$ is equal to $(x . n) / V, V$ is the unit cell volume ( $V=444.257 \AA$, from the JCPDS-26-1403 card), $x$ is the dopant concentration, and $n$ is the $\mathrm{Ba}^{2+}$ mol number per unit cell $(n=8$ from the JCPDS-26-1403 card). The estimated critical distance is shown in Table 1.

$R_{c}=\left[\frac{3}{4 \pi n_{A}}\right]^{1 / 3}$

The calculated $R_{C}$ indicates that an exchange interaction is unlikely to take place since the values are higher than $4 \AA$. Thus, the multipolar interaction must be the main factor that contributes to the energy transfer mechanism.

In order to investigate the dominant multipolar mechanism responsible for the ET between $\mathrm{Eu}^{3+}$ and $\mathrm{Tb}^{3+}$ ions, it was used the theoretical model developed by Van Uitert [30] showed in the Eq. (3), where $x$ is the acceptor concentration, $I$ is the emission intensity obtained from the emission spectra, and $\beta$ is a constant. In this model, $\theta$ is a function of the dominant ET mechanism between the donor and acceptor species. Electric dipole-dipole (D-D) interactions are represented by $\theta=6$, electric dipole-quadrupole (D-Q) interactions correspond to $\theta=8$ and electric quadrupole-quadrupole (Q-Q) interactions, in turn, are represented by $\theta=10$. In Fig. 5 it is plotted the log $(x)$ versus $\log (I / x)$, where the intensity was fixed in both $\mathrm{Tb}^{3+}{ }^{5} \mathrm{D}_{4} \rightarrow{ }^{7} \mathrm{~F}_{5}$ and $\mathrm{Eu}^{3+}{ }^{5} \mathrm{D}_{0} \rightarrow{ }^{7} \mathrm{~F}_{2}$ transitions. The $\theta$ values deduced from the fitting plots monitoring the emission of both RE ions are closer to 6, suggesting that $\mathrm{D}-\mathrm{D}$ interaction are the main contribution for the ET between $\mathrm{Tb}^{3+}$ and $\mathrm{Eu}^{3+}$ ions in the $\mathrm{Ba}_{2} \mathrm{SiO}_{4}$ matrix.

$\frac{I}{x}=\left[1+\beta(x)^{\theta / 3}\right]^{-1}$

The CIE chromaticity coordinates obtained for all phosphors are presented in the diagram in Fig. 6 . When the $\mathrm{Tb}^{3+}$ concentration is fixed at $1 \%$, the emission moves to pink, when the $\mathrm{Eu}^{3+}$ concentration increase from 0.01 up to $1 \%$, then goes back to red. This occurs because the $\mathrm{Tb}^{3+}$ emission is favored up to $1 \%$ of $\mathrm{Eu}^{3+}$, from then on, the $\mathrm{Eu}^{3+}$ emission overcomes the $\mathrm{Tb}^{3+}$ emission. Samples with equal RE concentration emit near to pink, since both red and blue emissions of $\mathrm{Eu}^{3+}$ and $\mathrm{Tb}^{3+}$ respectively have similar intensities. The phosphors with low $\mathrm{Tb}^{3+}$ concentration emit near to pink due to the blue contribution of the matrix emission. Thus, the emission color is tunable by varying the dopant concentration.

The Judd-Ofelt intensity parameters were evaluated from the emission spectra data and its values are summarized in Table 2. In this theory, the ${ }^{5} \mathrm{D}_{0} \rightarrow{ }^{7} \mathrm{~F}_{2}$ and ${ }^{5} \mathrm{D}_{0} \rightarrow{ }^{7} \mathrm{~F}_{4}$ transitions are directly correlated to $\Omega_{2}$ and $\Omega_{4}$ intensity parameters, which can be calculated from the integrated areas below the transitions ${ }^{5} \mathrm{D}_{0} \rightarrow{ }^{7} \mathrm{~F}_{1},{ }^{5} \mathrm{D}_{0} \rightarrow{ }^{7} \mathrm{~F}_{2}$, and ${ }^{5} \mathrm{D}_{0} \rightarrow{ }^{7} \mathrm{~F}_{4}$, as shown in Eqs. (4) and (5) [32].

$A_{0-\lambda}=A_{0-j}=A_{01} \frac{I_{0-j}}{I_{0-1}} \frac{h v_{0-1}}{h v_{0-j}}$

$\sum_{\lambda=2,4} \Omega_{\lambda}\left\langle{ }^{5} D_{0}\right\rangle^{2}=A_{01} \frac{I_{0-j}}{I_{0-1}} \frac{h v_{0-1}}{h v_{0-j}} \frac{3 h c^{3} 4 \epsilon_{0}}{64 \pi^{3} e^{2}} \frac{1}{v_{\lambda}^{3} x}$

Where the term $\left\langle D_{0}^{5}\right\rangle^{2}$ represent the square reduced matrix elements which is equal to 0.0032 and 0.0023 for $\Omega_{2}$ and $\Omega_{4}$; respectively [32]; $e$, $h, \varepsilon_{0}$ and $c$ are the electron charge, the Planck's constant, the vacuum permittivity constant; and the speed of light in vacuum, respectively; $A_{01}$ is equal to 14.65.n [3] ( $n$ is the refractive index considered in this case as 1.7 [13]) and corresponds to the Einstein's coefficient for spontaneous emission [33]; $I_{0-\mathrm{j}}$ is the integrated area under the respective ${ }^{5} \mathrm{D}_{0} \rightarrow{ }^{7} \mathrm{~F}_{j}$ transitions; and $x$ is given by $n\left(n^{2}+2\right)^{2} / 9$ and corresponds to the Lorentz local field correction.

The relatively low values of $\Omega_{4}$ compared to other systems $[34,35]$ indicate that the chemical environment around $\mathrm{Eu}^{3+}$ is low polarizable, suggesting a low covalence degree of the Eu-O bond, since the $\Omega_{4}$ intensity parameter is more sensitive to changes in the electron density around the $\mathrm{Eu}^{3+}$, caused by variations in the Eu-O bond distance [36]. On the other hand, the $\Omega_{2}$ value is more sensitive to changes in the $\mathrm{Eu}^{3+}$ site symmetry related to angular distortions in the Eu-O bonds [37]. The relatively low values of $\Omega_{2}$ intensity parameters compared to other systems $[34,35]$ indicate that the environment around the $\mathrm{Eu}^{3+}$ ions is relatively symmetric. This occurs because the doping does not cause strong distortions in the $\mathrm{Eu}^{3+}$ sites [13]. Also, there is a tendency of enhancement for the $\Omega_{2}$ values when the $\mathrm{Eu}^{3+}$ concentration increase, showing that the $\mathrm{Eu}^{3+}$ local symmetry is lowered. The ${ }^{5} \mathrm{D}_{0} \rightarrow{ }^{7} \mathrm{~F}_{2}$ is considered hypersensitive to the environment, and its intensity increase as the symmetry around the $\mathrm{Eu}^{3+}$ ion decrease.

Emission lifetime $(\tau)$ data shown in Table 2 were obtained by monitoring the $\mathrm{Eu}^{3+}{ }^{5} \mathrm{D}_{0}$ excited level and $\mathrm{Tb}^{3+5} \mathrm{D}_{3}$ and ${ }^{5} \mathrm{D}_{4}$ levels. The obtained curves are shown in Fig. S7 and were best adjusted by applying a mono-exponential fit. The $\mathrm{Tb}^{3+}$ lifetime values were used to estimate the $\mathrm{Tb} \rightarrow$ Eu ET efficiency by applying Eq. (6) [38], where $\tau_{1}$ is the lifetime value for the codoped sample and $\tau_{10}$ is the lifetime value for the $\mathrm{Tb}^{3+}$ single doped samples. The emission spectra for the single doped $\mathrm{Ba}_{2} \mathrm{SiO}_{4}: \mathrm{Tb}^{3+}(2 \%, 1 \%, 0.5 \%$ and $0.1 \%$-doped) are shown in Fig. S7 and the ET efficiencies are shown in Table 2.

$\eta_{T b \rightarrow E u}=1-\frac{\tau_{1}}{\tau_{10}}$

From Table 2, the $\mathrm{Tb} \rightarrow$ Eu ET efficiency increase in the samples that have $\mathrm{Eu}^{3+}$ content much lower or higher than that of $\mathrm{Tb}^{3+}$, showing that the $\mathrm{Tb} \rightarrow$ Eu ET prevails in relation to the opposite process. In these cases, the ET efficiency value from the $\mathrm{Tb}^{3+}{ }^{5} \mathrm{D}_{3}$ level is higher than that from the ${ }^{5} \mathrm{D}_{4}$ one, showing that the $\mathrm{Tb} \rightarrow$ Eu ET occurs mainly via the $\mathrm{Tb}^{3+}{ }^{5} \mathrm{D}_{3}$ level. As expected from the emission spectra, when the $\mathrm{Tb}^{3+}$ content is much lower than that of $\mathrm{Eu}^{3+}(\mathrm{Tb}(0.5) \mathrm{Eu}(4)$ and $\mathrm{Tb}$ (0.1)Eu(4)), the ET efficiency from both ${ }^{5} \mathrm{D}_{3}$ and ${ }^{5} \mathrm{D}_{4}$ levels are $100 \%$, indicating that this is the best condition to improve the $\mathrm{Eu}^{3+}$ efficiency. This efficient $\mathrm{Tb} \rightarrow$ Eu ET can also be evidenced by the increase of the $\mathrm{Eu}^{3+}{ }^{5} \mathrm{D}_{0}$ lifetime values for these samples when compared to the single doped $\mathrm{Ba}_{2} \mathrm{SiO}_{4}: \mathrm{Eu}^{3+}$ (compare in Table 1 the lifetime values for the samples single-doped or codoped with $4 \%$ of $\mathrm{Eu}^{3+}$ ). 

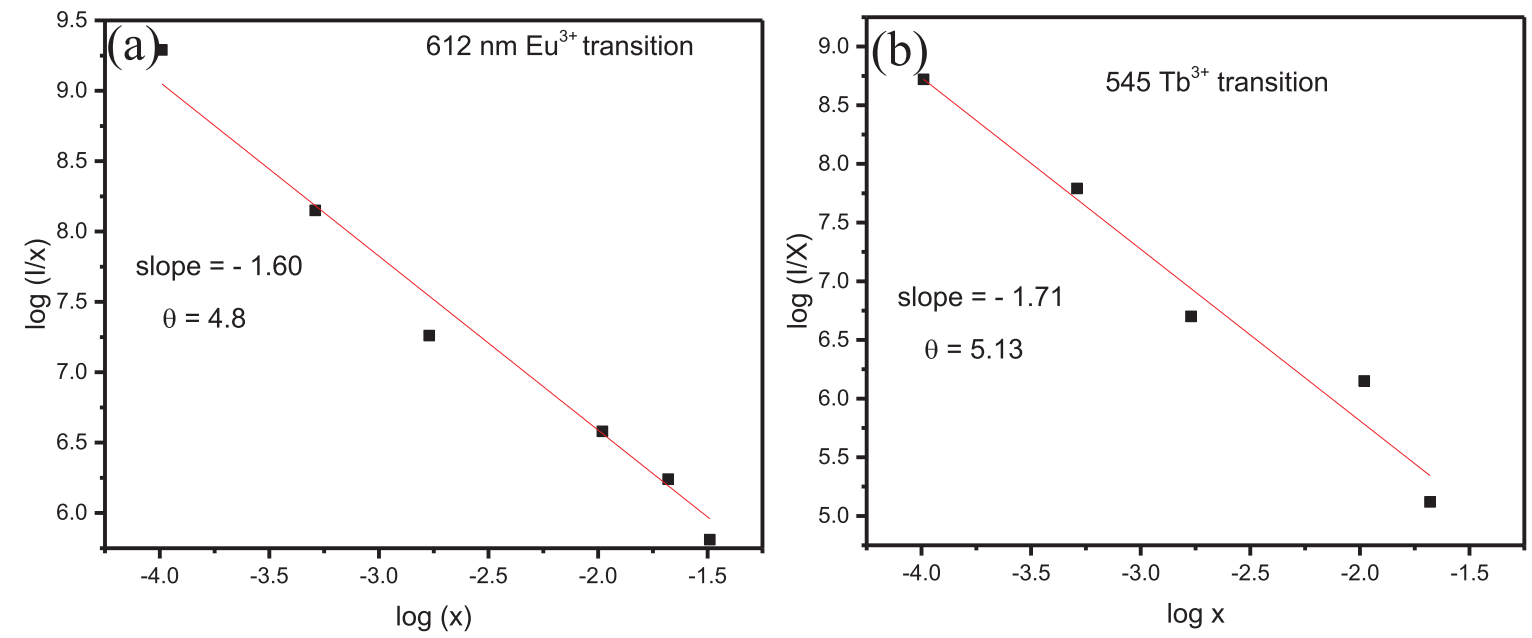

Fig. 5. Linear fitting of $\log (x)$ versus $\log (I / x)$ for $\mathrm{Ba}_{2} \mathrm{SiO}_{4}: \mathrm{Eu}^{3+}(\mathrm{x} \%), \mathrm{Tb}^{3+}(1 \%)$ phosphors considering the emission intensity at (a) $612 \mathrm{~nm}$ and (b) $545 \mathrm{~nm}$.



Fig. 6. $\mathrm{CIE}$ chromaticity diagram for the $\mathrm{Tb}^{3+}$ and $\mathrm{Eu}^{3+}$-codoped $\mathrm{Ba}_{2} \mathrm{SiO}_{4}$ obtained from Spectra Lux software [31], and the emission spectra collected under $250 \mathrm{~nm}$ excitation measured at room temperature.

When the $\mathrm{Eu}^{3+}$ and $\mathrm{Tb}^{3+}$ contents are similar (samples doped with $\mathrm{Tb}(1) \mathrm{Eu}(1), \mathrm{Tb}(0.5) \mathrm{Eu}(0.5), \mathrm{Tb}(2) \mathrm{Eu}(2)$ and $\mathrm{Tb}(0.5) \mathrm{Eu}(1))$, the $\mathrm{Tb} \rightarrow \mathrm{Eu}$ ET efficiency for the ${ }^{5} \mathrm{D}_{3}$ level is lower than that of the others, and the ET efficiency from the ${ }^{5} \mathrm{D}_{4}$ level is higher than $100 \%$ or very low. These results show that in the ${ }^{5} \mathrm{D}_{3}$ level, the $\mathrm{Eu} \rightarrow \mathrm{Tb}$ ET is more efficient for the ${ }^{5} \mathrm{D}_{3}$ level population in relation to the other samples, and as consequence, decrease the $\mathrm{Tb} \rightarrow$ Eu ET efficiency. Yet considering the ${ }^{5} \mathrm{D}_{4}$ level, a $\mathrm{Tb} \rightarrow$ Eu ET efficiency higher than $100 \%$ indicates that the opposite process is the main ET process, contributing to the population of the ${ }^{5} \mathrm{D}_{4}$ level and its lifetime value increase. Also, in some cases, a low ${ }^{5} \mathrm{D}_{4} \mathrm{~Tb} \rightarrow \mathrm{Eu}$ ET efficiency is an indicative that the opposite ET process is dominating. In this context, the Eu $\rightarrow \mathrm{Tb}$ ET occurs mainly via the ${ }^{5} \mathrm{D}_{4}$ level.

The $\mathrm{Eu}^{3+}{ }^{5} \mathrm{D}_{0}$ lifetime values were used to estimate the $\mathrm{Eu}^{3+}$ quantum efficiency $\left(\eta_{\mathrm{Eu}}\right)$ also shown in Table 2 . The quantum efficiency is the greatness that correlate the radiative $\left(\mathrm{A}_{\mathrm{rad}}\right)$ and the non-radiative $\left(A_{\text {nrad }}\right)$ contributions from an emitting level (Eq. (7)) [32].

$\eta=\frac{A_{\text {rad }}}{A_{\text {rad }}+A_{\text {nrad }}}$
The $\mathrm{A}_{\mathrm{rad}}$ contributions are calculated by the main radiative contributions related to the ${ }^{5} \mathrm{D}_{0} \rightarrow{ }^{7} \mathrm{~F}_{1} \mathrm{Eu}^{3+}$ transitions, as shown in Eq. (8) [32]. Yet, the $A_{\text {nrad }}$ values are determined directly from the lifetime values, as represented in Eq. (9) [32].

$A_{\text {rad }}=\sum^{J} A_{0-j}$

$A_{\text {total }}=\frac{1}{\tau}=A_{\text {rad }}+A_{\text {nrad }}$

For samples doped with $1 \%$ of $\mathrm{Tb}^{3+}$, the $\eta_{\mathrm{Eu}}$ decrease when the $\mathrm{Eu}^{3+}$ concentration increase up to $2 \%$, from then on, the $\eta_{\mathrm{Eu}}$ has an increment. The reduction of $\eta_{\mathrm{Eu}}$ is due to the $\mathrm{Eu}^{3+} \rightarrow \mathrm{Tb}^{3+}$ ET that overcomes the opposite process in these samples, as previously discussed, decreasing the population of $\mathrm{Eu}^{3+}{ }^{5} \mathrm{D}_{0}$ level. However, as the $\mathrm{Eu}^{3+} \rightarrow \mathrm{Tb}^{3+} \mathrm{ET}$ is not efficient at high $\mathrm{Eu}^{3+}$ doping concentration, the $\mathrm{Tb}^{3+} \rightarrow \mathrm{Eu}^{3+} \mathrm{ET}$ is the dominant process and, as consequence, increase the population of the $\mathrm{Eu}^{3+}{ }^{5} \mathrm{D}_{0}$ level. A similar profile is observed for samples doped with $0.5 \%$ of $\mathrm{Tb}^{3+}$.

The $\mathrm{Tb}^{3+}$ ions are acting as sensitizer for the $\mathrm{Eu}^{3+}$ ions in some specific conditions. Recently, we reported the $\eta_{\mathrm{Eu}}$ for the $\mathrm{Eu}^{3+} 4 \%$ doped sample as $68.2 \%$, as shown in Table 2 [13]. However, when we doped this sample with $0.5 \%$ or $0.1 \%$ of $\mathrm{Tb}^{3+}$, the $\eta_{\mathrm{Eu}}$ increase to $77.9 \%$ and $88.9 \%$, respectively, enhancing in $20 \%$ the $\mathrm{Eu}^{3+}$ quantum efficiency. This occurs because the $\mathrm{Tb}^{3+} \rightarrow \mathrm{Eu}^{3+} \mathrm{ET}$ is high and the $\mathrm{Tb}^{3+}$ ions act as sensitizers to the $\mathrm{Eu}^{3+}$ ions, increasing the ${ }^{5} \mathrm{D}_{0}$ level population and as consequence, enhances the $\mathrm{Eu}^{3+}$ radiative rate, and its quantum efficiency.

\section{Conclusions}

An energy transfer approach between $\mathrm{Eu}^{3+}$ and $\mathrm{Tb}^{3+}$ ions in monophasic $\mathrm{Ba}_{2} \mathrm{SiO}_{4}$ matrix successfully prepared by the sol-gel route was proposed. Both $\mathrm{Eu}^{3+}$ and $\mathrm{Tb}^{3+}$ emissions could be detected under $250 \mathrm{~nm}$ excitation, with an unexpected intense $\mathrm{Tb}^{3+}$ blue emission from the ${ }^{5} \mathrm{D}_{3}$ level at relatively high $\mathrm{Tb}^{3+}$ concentration. However, at relatively high $\mathrm{Eu}^{3+}$ concentrations, the $\mathrm{Tb}^{3+}$ emission was quenched. It was possible to tune the phosphor emission from red to pink by varying the $\mathrm{Eu}^{3+}$ and $\mathrm{Tb}^{3+}$ content. Considering all doping studied combinations, the energy transfer from $\mathrm{Tb}^{3+}$ to $\mathrm{Eu}^{3+}$ ions is taking place in all samples, but the inverse process only dominates when both $\mathrm{Tb}^{3+}$ and $\mathrm{Eu}^{3+}$ content are similar. The $\mathrm{Tb} \rightarrow$ Eu ET occurs mainly from the $\mathrm{Tb}^{3+}{ }^{5} \mathrm{D}_{3}$ level to the $\mathrm{Eu}^{3+}$ excited levels but the $\mathrm{Eu} \rightarrow \mathrm{Tb}$ ET occurs mainly from the $\mathrm{Eu}^{3+}$ excited levels to the $\mathrm{Tb}^{3+}{ }^{5} \mathrm{D}_{3}$ one. Also, when the $\mathrm{Eu}^{3+}$ content is much higher than the $\mathrm{Tb}^{3+}$ concentration, the $\mathrm{Eu}^{3+}$ quantum efficiency increase, due to the $\mathrm{Tb}^{3+} \rightarrow \mathrm{Eu}^{3+} \mathrm{ET}$, showing that 
Table 2

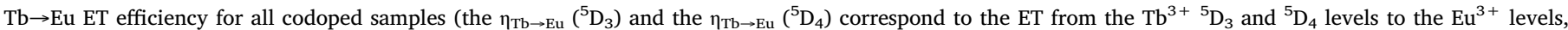


$\mathrm{Eu}^{3+}$ quantum efficiency $\left(\eta_{\mathrm{Eu}}\right)$ for the prepared phosphors.

\begin{tabular}{|c|c|c|c|c|c|c|c|c|}
\hline Tb/Eu (\%) & $\eta_{\mathrm{Tb} \rightarrow \mathrm{Eu}}\left({ }^{5} \mathrm{D}_{3}\right) / \%$ & $\eta_{\mathrm{Tb} \rightarrow \mathrm{Eu}}\left({ }^{5} \mathrm{D}_{4}\right) / \%$ & $\tau_{\mathrm{Tb}}{ }^{5} \mathrm{D}_{3} / \mathrm{ms}$ & $\tau_{\mathrm{Tb}}{ }^{5} \mathrm{D}_{4} / \mathrm{ms}$ & $\Omega_{2} / \mathrm{pm}$ & $\Omega_{4} / \mathrm{pm}$ & $\tau_{\mathrm{Eu}} / \mathrm{ms}$ & $\eta_{\text {Eu }} / \%$ \\
\hline $2 / 2$ & 78 & 108 & 0.43 & 1.53 & 5.59 & 4.80 & 0.73 & 33.8 \\
\hline $2 / 0.1$ & 82 & 12 & 0.36 & 1.24 & 4.66 & 4.69 & 1.36 & 56.1 \\
\hline $1 / 3$ & $100^{\mathrm{a}}$ & $100^{\mathrm{a}}$ & $-\mathrm{b}$ & $-\mathrm{b}$ & 5.69 & 5.18 & 0.99 & 46.7 \\
\hline $1 / 2$ & $100^{\mathrm{a}}$ & $100^{\mathrm{a}}$ & $-{ }^{b}$ & $-\mathrm{b}$ & 5.81 & 5.22 & 0.57 & 27.3 \\
\hline $1 / 1$ & 91 & 8 & 0.20 & 1.26 & 5.30 & 4.74 & 0.83 & 37.5 \\
\hline $1 / 0.1$ & 91 & 17 & 0.20 & 1.14 & 4.98 & 4.96 & 1.28 & 55.4 \\
\hline $1 / 0.05$ & 92 & 12 & 0.18 & 1.21 & 4.57 & 4.60 & 1.22 & 49.6 \\
\hline $1 / 0.01$ & 100 & 12 & $-\mathrm{b}$ & 1.22 & 4.65 & 4.90 & 1.49 & 61.1 \\
\hline $0.5 / 4$ & $100^{\mathrm{a}}$ & $100^{\mathrm{a}}$ & $-{ }^{b}$ & $-\mathrm{b}$ & 5.90 & 4.57 & 1.67 & 77.9 \\
\hline $0.5 / 1$ & 90 & 136 & 0.27 & 1.80 & 5.11 & 4.40 & 1.26 & 54.4 \\
\hline $0.5 / 0.5$ & 84 & 114 & 0.43 & 1.51 & 5.25 & 3.90 & 1.37 & 58.7 \\
\hline $0.1 / 4$ & $100^{\mathrm{a}}$ & $100^{\mathrm{a}}$ & - b & $-\mathrm{b}$ & 5.74 & 4.25 & 1.97 & 88.9 \\
\hline $0 / 4$ [13] & - & - & - & - & 6.20 & 6.10 & 1.34 & 68.2 \\
\hline $0 / 3$ [13] & - & - & - & - & 6.20 & 7.20 & 1.29 & 58.8 \\
\hline $0 / 2$ [13] & - & - & - & - & 6.40 & 5.60 & 1.11 & 55.6 \\
\hline $0 / 1[13]$ & - & - & - & - & 5.90 & 5.90 & 1.33 & 66.5 \\
\hline $2 / 0$ & - & - & 1.92 & 1.41 & - & - & - & - \\
\hline $1 / 0$ & - & - & 2.21 & 1.37 & - & - & - & - \\
\hline $0.5 / 0$ & - & - & 2.71 & 1.32 & - & - & - & - \\
\hline $0.1 / 0$ & - & - & 3.33 & 1.31 & - & - & - & - \\
\hline
\end{tabular}

a For the samples that do not have ${ }^{5} \mathrm{D}_{3}$ and ${ }^{5} \mathrm{D}_{4}$ lifetime values, the $\mathrm{Tb} \rightarrow$ Eu ET efficiency was considered as $100 \%$.

b Some samples do not shown $\mathrm{Tb}^{3+}$ emission and as consequence do not have lifetime values.

$\mathrm{Tb}^{3+}$ ions is acting as sensitizer to $\mathrm{Eu}^{3+}$ ions. Finally, the energy transfer between the doping ions is dominated by the dipole-dipole multipolar interactions.

\section{Acknowledgements}

The authors are thankful to the Brazilian agencies CNPq (307385/ 2015), CAPES, and FAPESP for the financial research support. Airton G. B. Junior is grateful to FAPESP for the award of some scholarships (Grant No.2012/13876-9, 2015/10394-1, and 2016/20421-9). The authors thank to Laboratório de Microscopia Eletrônica de Varredura (FCT-UNESP), research group in sol-gel (UNIFRAN), and Laboratório de compósitos e cerâmicas funcionais (FCT-UNESP).

\section{Conflicts of interest}

There are no conflicts to declare.

\section{Appendix A. Supporting information}

Supplementary data associated with this article can be found in the online version at doi:10.1016/j.jlumin.2018.03.057.

\section{References}

[1] G. Gasparotto, M.A. Cebim, M.S. Goes, S.A.M. Lima, M.R. Davolos, J.A. Varela, C.O. Paiva-Santos, M.A. Zaghete, Correlation between the spectroscopic and structural properties with the occupation of $\mathrm{Eu}^{3+}$ sites in powdered $\mathrm{Eu}^{3+}$-doped $\mathrm{LiTaO}_{3}$ prepared by the Pechini method, J. Appl. Phys. 106 (2009) (063509-5.).

[2] L. Chen, C. Lin, C. Yeh, R. Liu, Light converting inorganic phosphors for white lightemitting diodes, Materials (3) (2010) 2172-2195.

[3] Z. Wang, S. Guo, Q. Li, X. Zhang, T. Li, P. Li, Z. Yang, Q. Guo, Luminescent properties of $\mathrm{Ba}_{2} \mathrm{SiO}_{4}: \mathrm{Eu}^{3+}$ for white light emitting diodes, Physica B (2013) 110-113.

[4] F. Steudel, S. Loos, B. Ahrens, S. Schweizer, Quantum efficiency and energy transfer processes in rare-earth doped borate glass for solid-state lighting, J. Lumin. 170 (2016) 770-777.

[5] H. Ji, L. Wang, M.S. Molokeev, N. Hirosaki, R. Xie, Z. Huang, Z. Xia, O.M. ten Kate, Li Liub, V.V. Atuchin, New garnet structure phosphors, $\mathrm{Lu}_{3-x} \mathrm{Y}_{\mathrm{x}} \mathrm{MgAl}_{3} \mathrm{SiO}_{12}: \mathrm{Ce}^{3+}$ (x = 0-3), developed by solid solution design, J. Mater. Chem. C. 4 (2016) 2359-2366.

[6] Koen Binnemans, Interpretation of europium(III) spectra, Coord. Chem. Rev. 295 (2015) 1-45.

[7] S.A.M. Lima, F.A. Sigoli, M.R. Davolos, M. Jafelicci Jr., Europium(III)-containing zinc oxide from Pechini method, J. Alloy. Compd. 344 (2002) 280-284.
[8] J.G. Bunzli, Lanthanide luminescence for biomedical analyses and imaging, Chem. Rev. 110 (2010) 2729-2755.

[9] S.V. Eliseeva, J.G. Bunzli, Lanthanide luminescence for functional materials and bio-sciences, Chem. Soc. Rev. 39 (2010) 189-227.

[10] A.A. Silva, M.A. Cebim, M.R. Davolos, Excitation mechanisms and effects of dopant concentration in $\mathrm{Gd}_{2} \mathrm{O}_{2} \mathrm{~S}: \mathrm{Tb}^{3+}$ phosphor, J. Lumin. 128 (2008) 1165-1168.

[11] A.M. Pires, M.R. Davolos, Luminescence of Europium(III) and Manganese(II) in barium and zinc orthosilicate, Chem. Mater. 13 (2001) 21-27.

[12] A.M. Pires, M.R. Davolos, O.L. Malta, $\mathrm{Eu}^{3+}-\mathrm{O}^{2-}$ associates luminescence in $\mathrm{Ba}_{2} \mathrm{SiO}_{4}$, J. Lumin. 72 (1997) 244-246.

[13] A.G. Bispo-Jr, D.A. Ceccato, S.A.M. Lima, A.M. Pires, Red phosphor based on $\mathrm{Eu}^{3+}$ isoelectronically doped $\mathrm{Ba}_{2} \mathrm{SiO}_{4}$ obtained via sol-gel route for solid state lightning, RSC Adv. 7 (2017) 53752-53762.

[14] F. Steudel, S. Loos, B. Ahrens, S. Schweizer, Quantum efficiency and energy transfer processes in rare-earth doped borate glass for solid-state lighting, J. Lumin. 170 (2016) 770-777.

[15] L. Zhou, B. Yan, Synthesis, microstructure and photoluminescence of Eu3 + /Tb3+ activated $\mathrm{Y}_{2} \mathrm{SiO}_{5}$ nanophosphors by new silicate sources, Appl. Surf. Sci. 254 (2008) 1847-1851.

[16] W. Guo, Y. Tian, P. Huang, L. Wang, Q. Shi, C. Cui, Color tunable luminescence in novel $\mathrm{Li}_{3} \mathrm{Ba}_{2} \mathrm{Y}_{3}\left(\mathrm{WO}_{4}\right)_{8}: \mathrm{Tb}^{3+}, \mathrm{Eu}^{3+}$ phosphor for white LEDs, Ceram. Int. 42 (2016) 5427-5432.

[17] S. Som, S.K. Sharma, $\mathrm{Eu}^{3+} / \mathrm{Tb}^{3+}$-codoped $\mathrm{Y}_{2} \mathrm{O}_{3}$ nanophosphors: Rietveld refinement, bandgap and photoluminescence optimization, J. Phys. D: Appl. Phys. 45 (2012) 415102

[18] A.J. Fernández-Carrión, M. Ocaña, J. García-Sevillano, E. Cantelar, A. Isabel Becerro, New single-phase, white-light-emitting phosphors based on $\delta-\mathrm{Gd}_{2} \mathrm{Si}_{2} \mathrm{O}_{7}$ for solid-state lighting, J. Phys. Chem. C 118 (2014) 18035-18043.

[19] M.A. Tshabalala, H.C. Swart, O.M. Ntwaeaborwa, TOF SIMS analysis and generation of white photoluminescence from strontium silicate codoped with europium and terbium, J. Vac. Sci. Technol. A 32 (2014) 021401-021406.

[20] P.A. Raymundo-Pereira, D.A. Ceccato, D., A.G.B. Junior, M.F.S. Teixeira, S.A.M. Lima, A.M. Pires, Study on the structural and electrocatalytic properties of $\mathrm{Ba}^{2+}$ - and $\mathrm{Eu}^{3+}$-doped silica xerogelsas sensory platforms, RSC Adv. 6 (2016) 104529-104536.

[21] J.K. Han, M.E. Hannah, A. Piquette, J.B. Talbot, K.C. Mishra, J. McKittrick, Europium-activated $\mathrm{KSrPO}_{4}-(\mathrm{Ba}, \mathrm{Sr})_{2} \mathrm{SiO}_{4}$ solid solutions as color-tunable phosphors for near-UV light-emitting diode applications, J. Am. Ceram. Soc. 96 (2013) 526-1532.

[22] A.L. Patterson, The scherrer formula for x-ray particle size determination, Phys. Rev. 56 (1939) 978-982.

[23] I. Couwenberg, K. Binnemans, H. De Leebeeck, C. Gorller-Walrand, Spectroscopic properties of the trivalent terbium ion in the huntite matrix $\mathrm{TbAl}_{3}\left(\mathrm{BO}_{3}\right)_{4}$, J. Alloy. Compd. 274 (1998) 157-163.

[24] W.T. Carnall, G.L. Goodman, K. Rajnak, R.S. Rana, A systematic analysis of the spectra of the lanthanides doped into single crystal LaF 3 , J. Chem. Phys. 90 (1989) 3443-3457.

[25] Y. Fu, Y. Hu, A blue-green-emitting phosphor $\mathrm{Na}_{2} \mathrm{Ca}_{3} \mathrm{Si}_{2} \mathrm{O}_{8}: \mathrm{Tb}^{3+}$ with tunable emission color manipulated by cross-relaxation, J. Mater. Sci: Mater. Electron. 27 (2016) 3867-3872.

[26] J. Zhang, B. Chen, Z. Liang, X. Li, J. Sun, R. Zhong, L. Cheng, H. Zhong, Interionic cross relaxation and tunable color luminescence in $\mathrm{KY}_{3} \mathrm{~F}_{10}: \mathrm{Tb}^{3+}$ nano/microcrystals 
synthesized by hydrothermal approach, J. Fluor. Chem. 144 (2012) 1-6.

[27] N. Guo, C. Jia, J. Li, Y. Zhao, R. Ouyang, W. Lu, Color tuning and energy transfer in $\mathrm{Eu}^{2+} / \mathrm{Mn}^{2+}$-doped $\mathrm{Ba}_{3} \mathrm{Y}\left(\mathrm{PO}_{4}\right)_{3}$ eulytite-type orthophosphate phosphors, RSC Adv. 5 (2015) 46517-46524.

[28] O.L. Malta, Mechanisms of non-radiative energy transfer involving lanthanide ions revisited, J. Non-Cryst. Solids 354 (2008) 4770-4776.

[29] D.L. Dexter, J.H. Schulman, Theory of concentration quenching in inorganic phosphors, J. Chem. Phys. 22 (1954) 1063-1070.

[30] L.G. Uitert, Characterization of energy transfer interactions between rare earth ions, J. Electrochem. Soc. 14 (1967) 1048-1053.

[31] P.A. Santa-cruz, F.S. Teles, Spectra Lux Software. Versão 2.0 RENAMI, U. Federal de Pernambuco, 2003.

[32] G.F. de Saá, O.L. Malta, C. de Mello Donegaa, A.M. Simas, R.L. Longo, P.A. SantaCruz, E.F. da Silva Jr, Spectroscopic properties and design of highly luminescent lanthanide coordination complexes, Coord. Chem. Rev. 196 (2000) 165-195.
[33] A.P. Duarte, M. Gressier, M. Menu, J. Dexpert-Ghys, J.M.A. Caiut, S.J.L. Ribeiro Structural and luminescence properties of silica-based hybrids containing new silylated-diketonato europium(III) complex, J. Chem. Phys. C 116 (2012) 505-515.

[34] T. Grzyb, S. Lis, Structural and spectroscopic properties of LaOF:Eu ${ }^{3+}$ nanocrystals prepared by the sol-gel pechini method, Inorg. Chem. 50 (2011) 8112-8120.

[35] A.M. Pires, M.R. Davolos, E.B. Stucchi, Eu as a spectroscopic probe in phosphors based on spherical fine particle gadolinium compounds, Int. J. Inorg. Mater. 3 (2001) 785-790.

[36] T. Grzyb, S. Lis, Structural and spectroscopic properties of LaOF:Eu ${ }^{3+}$ nanocrystals prepared by the sol-gel pechini method, Inorg.Chem 50 (2011), pp. 8112-8120.

[37] W.T. Carnall, Handbook on the Physics and Chemistry of Rare Earths 3 (1979), p. 171.

[38] P. Ghosh, A. Kar, A. Patra, Energy transfer study between $\mathrm{Ce}^{3+}$ and $\mathrm{Tb}^{3+}$ ions in doped and core-shell sodium yttrium fluoride nanocrystals, Nanoscale 2 (2010) 1196-1202. 